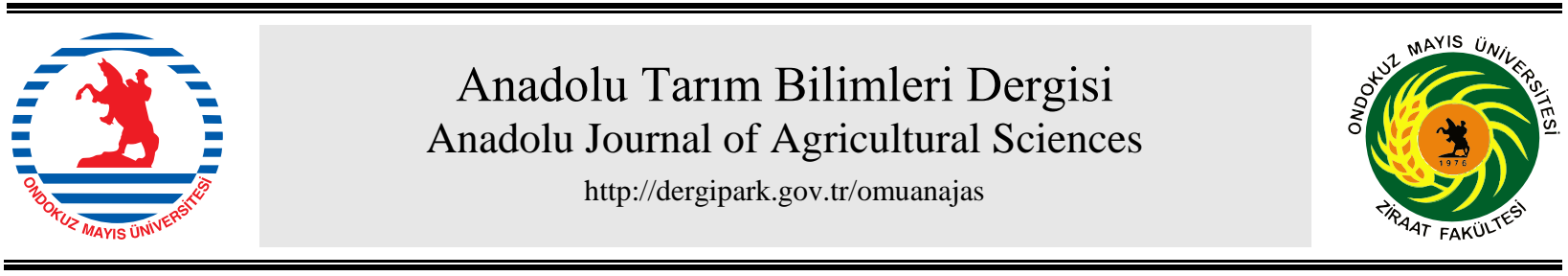

Araştırma/Research

Anadolu Tarım Bilim. Derg./Anadolu J Agr Sci, 32 (2017)

ISSN: 1308-8750 (Print) 1308-8769 (Online)

doi: 10.7161/omuanajas.289801

\title{
Çukurova koşullarında toprak işleme yöntemlerinin agregatlara bağlı toplam karbon ve azot içerikleri üzerine etkileri
}

\author{
İsmail Çelik*, Mert Acar \\ Çukurova Üniversitesi, Ziraat Fakültesi, Toprak Bilimi ve Bitki Besleme Bölümü \\ "Sorumlu Yazar: icelik@cu.edu.tr
}

Geliş/Received 04/02/2017 Kabul/Accepted 23/03/2017

\begin{abstract}
ÖZET
Çukurova koşullarında yaklaşık \% 50 oranında kil içeren bir toprakta uzun süreli (2006-2014) buğdaymisır ve buğday-soya rotasyonu altında altı farklı toprak işleme yönteminin iki farklı derinlikte (0-15 ve 15-30 cm) agregatlara bağlı toplam karbon ve azot içeriğine etkileri araştırılmıştır. Toprak işleme uygulamaları olarak; Anızlı geleneksel toprak işleme (Gí-1), Anızları yakılmış geleneksel toprak işleme (Ġं-2), Ağır diskli tırmıklı azaltılmış toprak işleme (ATİ-1), Rototillerli azaltılmış toprak işleme (ATİ2), Ağır diskli tırmıklı azaltılmış sıfır toprak işleme (ASTİ) ve Doğrudan ekimli sıfır toprak işleme (STI) yöntemleri kullanılmıştır. Her bir işleme yöntemi $480 \mathrm{~m}^{2}$ 'lik alana uygulanmakta ve 3 tekerrürlü tesadüf parselinden oluşmaktadır. $0-15 \mathrm{~cm}$ derinlikte bütün agregat boyutlarında $(>4.0 \mathrm{~mm}, 4.0-2.0 \mathrm{~mm}$, 2.0-1.0 mm ve 1.0-0.5 mm) toplam karbon değerleri geleneksel işleme yöntemlerine kıyasla korumalı işleme uygulamaları altında daha yüksek değerler elde edilmiştir. Derinlikteki artışla birlikte korumalı işleme yöntemleri altındaki agregatlarda bulunan toplam karbon değerleri azalmıştır. Her iki derinlikte $(0-15 \mathrm{~cm}$ ve $15-30 \mathrm{~cm})$ ve bütün agregat boyutlarında $(>4.0 \mathrm{~mm}, 4.0-2.0 \mathrm{~mm}, 2.0-1.0 \mathrm{~mm}$ ve $1.0-0.5$ $\mathrm{mm}$ ) en yüksek toplam azot değerleri ATİ-1 işleme yöntemi altında belirlenmiştir. Korumalı işleme yöntemleri, geleneksel işleme yöntemlerine kıyasla agregatlar içerisinde toplam karbonun bağlanmasında önemli iyileşmeler sağladığı belirlenmiştir. ATİ-1 hariç diğer korumalı işleme yöntemlerinde (STİ, ASTİ ve ATİ-2) geleneksel işlemelere göre daha düşük toplam azot değerleri belirlenmiştir.
\end{abstract}

Effects of soil tillage systems on aggregate-associated total carbon and nitrogen contents under Çukurova conditions

\section{ABSTRACT}

The effect of six different tillage methods under long-term (2006-2014) wheat-maize and wheat-soy rotations on aggregate-assosicated total carbon and nitrogen content in two different depths (0-15, 15-30 $\mathrm{cm})$ were studied under Çukurova conditions in approximately $50 \%$ clay containing soil. The tillage systems consisted of conventional tillage with stubble (CT-1), conventional tillage with stubbles burned (CT-2), heavy disc harrow reduced tillage (RT-1), rototiller reduced tillage (RT-2), reduced tillage with heavy tandem disc harrow fallowed by no-tillage (RNT), and no-till (NT). Each tillage method applied at $480 \mathrm{~m}^{2}$ plot and replicated three times in randomly distributed plots. Aggregate-associated total C contents in $0-15 \mathrm{~cm}$ depth were obtained higher in conservation tillage treatments compared to traditional tillage techniques at all aggregate sizes $(>4.0 \mathrm{~mm}, 4.0-2.0 \mathrm{~mm}, 2.0-1.0 \mathrm{~mm}$ and $1.0-0.5 \mathrm{~mm})$. Aggregate-associated total $\mathrm{C}$ values under conservation tillage methods decreased with increasing soil depth. In both depths $(0-15,15-30 \mathrm{~cm})$ and at all aggregate sizes the highest total nitrogen concentration values were determined in RT-1 tillage treatment. Significant enhancements of total carbon bounding in aggregates were observed in conservation tillage methods compared to traditional tillage methods. Except for RT-1 in other conservation tillage methods (NT, RNT and RT-2) total nitrogen values were lower compared to conventional tillage methods.

Anahtar Sözcükler:

Agregat

Korumalı işleme

Sifir işleme

Toplam azot

Toplam karbon

\section{Giriş}

Türkiye'deki toplam ekilebilir alanların \% $\quad 5$ 'ini kapsayan Çukurova bölgesi, sahip olduğu iklim, toprak ve su kaynakları avantajından ötürü bir yıl içerisinde en az iki ürün yetiştiriciliğinin yapıldığı bölgelerin başında
Keywords:

Aggregate

Conservation tillage

No-till

Total nitrogen

Total carbon

(C) OMU ANAJAS 2017 
gelmektedir. Yoğun tarımsal üretim faaliyetlerinin uygulandığı bu bölgede, topraklar bitkisel yetiştiricilikte kullanılırken daha çok geleneksel yöntem ve aletlerle yoğun bir şekilde işlenmektedir. Toprakların geleneksel yöntemlerle sürekli olarak derin, çok sayıda, yoğun ve parçalayıcı olarak işlenmesi sonucu toprakların kalite özelliklerini oluşturan fiziksel, kimyasal ve biyolojik özelliklerinde önemli bozunumlar meydana gelmektedir (Cannell ve Hawes, 1994; Lal, 1998; Pagliai ve ark., 2004). Bu özellikler arasında toprak strüktürü, toprak işleme sistemlerinden en çok ve çoğunlukla da olumsuz etkilenen toprak özelliklerinin başında gelmektedir (Kutilex, 2004).

İşleme esnasında makineler toprağı kırdı $\breve{g}_{1}$, çatlattığı ya da sıkıştırdığı için mekanik kuvvetlerin agregatları parçalama üzerine önemli bir etkisi bulunmaktadır (Blanco-Canqui ve Lal, 2006). Mikro agregatlardan ziyade makro agregatların, toprak işlemenin bu etkisine daha duyarlı olduğu bilinmektedir (Six ve ark., 2000; Christensen, 2001; Barbera ve ark., 2012). Sürekli olarak işlenen bir alanda topraktaki makro agregatlar bu şekilde parçalandığı için agregatlar tarafından korunan organik madde açığa çıkmaktadır (Nardi ve ark., 1996; Islam ve Weil, 2000). Bu yüzden toprağın toplam karbon ve azot içeriğginde mineralizasyona bağlı olarak azalmalar meydana gelmektedir. Buna karşın işlenmeyen veya geleneksel işleme yöntemlerine kıyasla daha az sayıda ve yoğunlukta işlenen koşullar altında gelişim gösteren makro agregatlar ise, daha yüksek organik karbon (Dexter, 1988; Jiang ve ark., 2011) ve daha yüksek toplam azot içeriğine (Kushwaha ve ark., 2001) sahiptir.

Kasper ve ark. (2009) yaptıkları bir çalışmada üç farkl1 agregat boyutunda $(0.63-1,0.25-0.63$ ve 0.063 $0.25 \mathrm{~mm}$ ) en yüksek organik karbon ve toplam azot değerlerinin minimum toprak işlemede saptandığını belirtmişlerdir. Kabiri ve ark. (2015) farklı işleme yöntemlerinin agregatlara bağlı organik madde değişimini inceledikleri araştırmalarında ise kulaklı pulluk ve diskli pullukla işlemeye kıyasla çizelle ve rototillerli işlemenin makro agregatları $(4.00-0.25 \mathrm{~mm})$ arttırdığını, buna karşılık mikro agregatları (0.250 $0.053 \mathrm{~mm}$ ) azaltı̆̆gnı rapor etmişlerdir. Ayrıca çizelle ve rototillerli işleme uygulamalarının mikro agregata bağlı karbon (\% 50 - \% 66) ve azot (\% 48 - \% 61) değerlerini azalttığı, makro agregata bağlı karbon (\% 10 - \% 11) ve azot $\left(\begin{array}{llll}\% & 13 & -\% & 15\end{array}\right)$ değerlerini ise arttırdığı da rapor edilmiştir.

Abid ve Lal (2008) drenajlı ve drenajsız koşullarda çizelle işleme ve sıfır işlemenin toprak kalitesine etkilerini araştırdıkları bir çalışmada, $0-10 \mathrm{~cm}$ derinlikte agregat boyut dağılımındaki organik karbon ve toplam azotun toprak işleme sistemlerinden önemli bir şekilde etkilendiğini ve bu değerlerin derinlikteki artışla birlikte azaldığını rapor etmişlerdir. Ayrıca $>1 \mathrm{~mm}$ boyutundaki agregatlarda organik karbon konsantrasyonunun, 1-2 $\mathrm{mm}$ boyutundaki agregatlarda ise toplam azotun sifir işlemede daha fazla olduğu da bildirilmiştir.

Geleneksel toprak işlemeye alternatif olacağı düşünülen korumalı toprak işleme yöntemlerinin agregatlara bağlı toplam karbon ve azot üzerine etkileri konusunda ülkemizdeki araştırmalar yetersiz kalmıştır. Özellikle toprak işleme yöntemlerinin hem ağır bünyeli topraktaki etkileri hem de bu yöntemlerin uzun süreli etkilerinin incelenmesine yönelik araştırmalar ise neredeyse hiç bulunmamaktadır. Bu nedenle Çukurova bölgesinde yaygın olarak yapılan kışlık buğday+mısır ya da kışlık buğday+soya bitki rotasyonunda uygulanan geleneksel toprak işleme, azaltılmış toprak işleme ve toprak işlemesiz (no-till) yöntemlerinin uzun süreli (9 yıllık) kullanımlarının killi bir toprakta (ort. \% 50 kil) agregatlara bağlı toplam karbon ve azot içeriğine etkileri belirlenmiştir.

\section{Materyal ve Yöntem}

\subsection{Araştırma alanı}

Araştırma, 2006 yılında Çukurova Üniversitesi Ziraat Fakültesi Araştırma ve Uygulama Çiftliği arazileri içerisinde yer alan Arık toprak serisi üzerinde kurulmuştur. Toprak taksonomisi sınıflandırma sistemine göre araştırmanın yürütüldüğü alandaki topraklar Vertisol ordosu, Haploxerert büyük grubunda ve Typic Haploxerert alt grubunda yer almaktadır (Soil Survey Staff, 1999).

Arık serisi toprakları, düz ve düze yakın $\% 0-1$ eğimli ve derin profilli, oldukça yaşlı alüviyal taban araziler üzerinde yer alan, A-C horizon dizilimine sahiptir. Tüm profil kil tekstürlü ve kireçli olup, çok az kireç yıkanması meydana gelmiştir (Gülez ve Şenol, 2002). Toprak serisi $0-30 \mathrm{~cm}$ derinlikte ortalama olarak $\% 50$ kil, \% 32 silt ve \% 18 kum içermekte, $\mathrm{pH}$ 's 7.82 , total tuz içeriği $\% 0.02$, kireç içeriği $\% 24.4$, organik karbon içeriği \% 0.88 ve hacim ağırlığ $1.31 \mathrm{~g} \mathrm{~cm}^{-3}$ dür (Çelik ve ark., 2009). Araştırma alanı tipik Akdeniz iklim kuşağında yer almakta olup, kışlar ılık ve yağışlı, yazlar sıcak ve kurak geçer. Araştırma alanına $3 \mathrm{~km}$ mesafede bulunan Adana İli Meteoroloji İstasyonu tarafindan kaydedilen 30 yıllık ortalama iklim verilerine göre ilin yıllık ortalama sıcaklığı $19.1{ }^{\circ} \mathrm{C}^{\prime}$ dir. Yıllık ortalama toplam buharlaşma miktarı $1536 \mathrm{~mm}$, toplam yağış miktarı ise $670 \mathrm{~mm}$ olup, bu yağışın \% 75'i kış ve ilkbahar aylarında düşmektedir.

\subsection{Deneme deseni ve toprak işleme sistemleri}

Araştırma alanı, 6 farklı toprak işleme sistemi için 3 tekerrürlü olarak toplam 18 adet tesadüf parselinden oluşmaktadır. Her bir tesadüf parseli $12 \mathrm{~m}$ uzunluğunda ve $40 \mathrm{~m}$ genişliğinde olmak üzere $480 \mathrm{~m}^{2}$ lik alan kapsamaktadır. Toprak işleme, sulama, gübreleme, bakım ve hasat işlemleri sırasında makine ve traktör işlemlerinde sorunlar yaşanmaması ve parsellerin zarar görmemesi için parsellerin çevresinde $4 \mathrm{~m}$ boşluk bırakılmıştır.

Araştırma parsellerine 2006 yllından bu yana korumalı ve geleneksel işleme sistemlerini içeren altı 
farklı toprak işleme yöntemi uygulanmaktadır. Bunlar sırasıyla: Anızlı geleneksel toprak işleme (GI-1), Anızları yakılmış geleneksel toprak işleme (Gİ-2), Ağır diskli tırmıklı azaltılmış toprak işleme (ATÍ-1), Rototillerli azaltılmış toprak işleme (ATİ-2), Ağır diskli tırmıklı azaltılmış sıfır toprak işleme (ASTI) ve Doğrudan ekimli sıfır toprak işlemedir (STI). Her bir toprak işleme sistemi 3 tekerrürlü tesadüf parselinden oluşmaktadır.

2006 yılından bu yana araştırma parsellerine altı farklı (Gİ-1, Gİ-2, ATİ-1, ATİ-2, ASTİ ve STI) toprak işleme sistemi uygulanarak kışlık bitki olarak (birinci ürün) her yıl buğday ve yazlık olarak (ikinci ürün) buğday hasadını takiben sırasıyla bir yıl mısır ve bir yıl soya yetiştirilmiştir. Birinci ve ikinci ürün yetiştiriciliğinde uygulanan toprak işleme yöntemlerine ait işlemlerin ayrıntıları Çizelge 1'de verilmiştir. ASTI konusunda kışlık ürün olan buğday ekim işleminde azaltılmış işlemenin uygulanması, ikinci ürün ekim işleminde ise sıfır işlemenin uygulanması nedeniyle (Çizelge 1) bu işleme sistemine "Ağır Diskli Tırmıklı Azaltılmış Sıfır Toprak İşleme" ismi verilmiştir. Yani ASTİ konusu, bir yıl içerisinde yetiştirilen iki ürün için hem sıfır işleme hem de azaltılmış işleme uygulamalarını kapsamaktadır.

Çizelge 1. Birinci ve ikinci ürünlerin ekiminde kullanılan toprak işleme yöntemleri

\begin{tabular}{|c|c|c|}
\hline Toprak İşleme Yöntemi & $\begin{array}{l}\text { Kişlik Ekim (Buğday) } \\
\text { İçin Toprak İşleme }\end{array}$ & $\begin{array}{c}\text { İkinci ürün (Misır/Soya) } \\
\text { İçin Toprak İşleme }\end{array}$ \\
\hline $\begin{array}{l}\text { Anızlı Geleneksel İşleme } \\
\text { (GÍ-1) }\end{array}$ & $\begin{array}{l}\text { - Anızların parçalanması } \\
\text { - Kulaklı pullukla işleme } \\
\text { - Diskli tırmık (Diskaro) (2 kez) } \\
\text { - Tapan ( } 2 \mathrm{Kez}) \\
\text { - Üniversal ekim makinası ile buğday } \\
\text { ekimi }\end{array}$ & $\begin{array}{l}\text { - Anızların parçalanması } \\
\text { - Ağır diskli tırmıkla (Goble) işleme } \\
\text { - Diskli tırmıkla işleme (2 kez) } \\
\text { - Tapan ( } 2 \mathrm{Kez}) \\
\text { - Pnömatik tek tohum ekim makinası ile } \\
\text { mısır/soya ekimi }\end{array}$ \\
\hline $\begin{array}{l}\text { Anızları Yakılmış } \\
\text { Geleneksel İşleme } \\
\text { (Gİ-2) }\end{array}$ & $\begin{array}{l}\text { - Anızların yakılması } \\
\text { - Kulaklı pullukla işleme } \\
\text { - Diskli tırmık (Diskaro) (2 kez) } \\
\text { - Tapan (2 Kez) } \\
\text { - Üniversal ekim makinası ile buğday } \\
\text { ekimi }\end{array}$ & $\begin{array}{l}\text { - Anızların yakılması } \\
\text { - Çizelle işleme } \\
\text { - Diskli tırmıkla işleme (2 kez) } \\
\text { - Tapan (2 Kez) } \\
\text { - Pnömatik tek tohum ekim makinası ile } \\
\text { mısır/soya ekimi }\end{array}$ \\
\hline $\begin{array}{l}\text { Ağır Diskli Tırmıklı } \\
\text { Azaltılmış Toprak İşleme } \\
\text { (ATİ-1) }\end{array}$ & $\begin{array}{l}\text { - Anızların parçalanması } \\
\text { - Ağır diskli tırmıkla (Goble) işleme } \\
\text { (2 kez) } \\
\text { - Tapan }(2 \mathrm{Kez}) \\
\text { - Üniversal ekim makinası ile buğday } \\
\text { ekimi }\end{array}$ & $\begin{array}{l}\text { - Anızların parçalanması } \\
\text { - Rototillerle işleme } \\
\text { - Tapan (2 Kez) } \\
\text { - Pnömatik tek tohum ekim makinası ile } \\
\text { mısır/soya ekimi }\end{array}$ \\
\hline $\begin{array}{l}\text { Rototillerli Azaltılmış } \\
\text { Toprak İşleme (ATİ-2) }\end{array}$ & $\begin{array}{l}\text { - Anızların parçalanması } \\
\text { - Rototillerle işleme } \\
\text { - Tapan ( } 2 \mathrm{Kez}) \\
\text { - Üniversal ekim makinası ile buğday } \\
\text { ekimi }\end{array}$ & $\begin{array}{l}\text { - Anızların parçalanması } \\
\text { - Rototillerle işleme } \\
\text { - Tapan (2 Kez) } \\
\text { - Pnömatik tek tohum ekim makinası ile } \\
\text { mısır/soya ekimi }\end{array}$ \\
\hline $\begin{array}{l}\text { A ğır Diskli Tırmıklı } \\
\text { Azaltılmış Sıfır Toprak } \\
\text { İşleme (ASTI) }\end{array}$ & $\begin{array}{l}\text { - Anızların parçalanması } \\
\text { - Ağır diskli tırmıkla (Goble) işleme } \\
\text { - Tapan ( } 2 \text { Kez) } \\
\text { - Üniversal ekim makinası ile buğday } \\
\text { ekimi }\end{array}$ & $\begin{array}{l}\text { - Anızların parçalanması } \\
\text { - Herbisit uygulama } \\
\text { - Pnömatik tek tohum ekim makinası ile } \\
\text { mısır/soya ekimi }\end{array}$ \\
\hline $\begin{array}{l}\text { Doğrudan Ekimli Sıfir } \\
\text { Toprak İşleme (STİ) }\end{array}$ & $\begin{array}{l}\text { - Anızların parçalanması } \\
\text { - Herbisit uygulama } \\
\text { - Doğrudan tahıl ekim makinası ile } \\
\text { buğday ekimi }\end{array}$ & $\begin{array}{l}\text { - Anızların parçalanması } \\
\text { - Herbisit uygulama } \\
\text { - Pnömatik tek tohum ekim makinası ile } \\
\text { misır/soya ekimi }\end{array}$ \\
\hline
\end{tabular}

\subsection{Araştırmada belirlenen toprak parametreleri}

Uzun süreli (2006-2014) korumalı ve geleneksel işleme uygulamalarının agregatlara bağlı toplam karbon ve azota etkilerini belirlemek amaciyla 2014 yilı kasım ayında kışlık buğday ekimi gerçekleştirilmeden önce (2014 yılı ikinci ürün soya hasadı sonrasında) tüm parsellerde bozulmuş toprak örnekleri alınmıştır.
Örnekler her parselin 3 farklı noktasından $0-15 \mathrm{~cm}$ ve $15-30 \mathrm{~cm}$ derinliklerinden alınmıştır. Alınan toprak örnek sayısı 108 adet olmakla birlikte bu alınan örnekler laboratuvar ortaminda kuru elemeye tabi tutularak 4 farkl $1>4.0 \mathrm{~mm}, 4.0-2.0 \mathrm{~mm}, 2.0-1.0 \mathrm{~mm}$ ve $1.0-0.5$ $\mathrm{mm}$ ) agregat boyutlarına ayrılmış ve toplam 432 adet toprak örneği elde edilmiştir. Elde edilen agregat büyüklüklerinde toplam karbon ve azot, Elemental 
Analiz Cihazı (Costech Ecs 4010 CHNSO Analyzer) kullanılarak kuru yakma yöntemine göre saptanmıştır.

\section{4. İstatistiki değerlendirme}

Araştırma topraklarından elde edilen sonuçların istatistiki analizlerinde tek yönlü varyans analizi (ANOVA) kullanılmıştır. İşlemler JMP bilgisayar programı kullanılarak gerçekleştirilmiş̧ir. Saptanan her toprak parametresinin parsellerdeki $0-15$ ve $15-30 \mathrm{~cm}$ derinlikteki ortalamalar arası farklılıkları LSD testi kullanılarak karşılaştırılmıştır.

\section{Bulgular ve Tartış̧a}

\subsection{Toprak işleme yöntemlerinin agregatlara bağlı toplam karbona etkisi}

İşleme uygulamalarının farklı büyüklükteki agregatlarda tutulan toplam karbon içerikleri üzerinde birbirinden farklı ve önemli düzeylerde etkileri olduğu belirlenmiştir (Şekil 1). İşleme uygulamalarının yüzey topraklarında bütün agregat boyutlarındaki $(>4.0 \mathrm{~mm}$, 4.0-2.0 mm, 2.0-1.0 mm ve 1.0-0.5 mm) toplam karbon üzerine etkileri \% 1 düzeyinde önemli çıkarken (Şekil 1a) yüzey altı topraklarında ise sadece $>4.0 \mathrm{~mm}$ ve 2.0 $1.0 \mathrm{~mm}$ sirasiyla $\% 5$ ve $\% 1$ düzeylerinde önemli bulunmuştur (Şekil 1b).
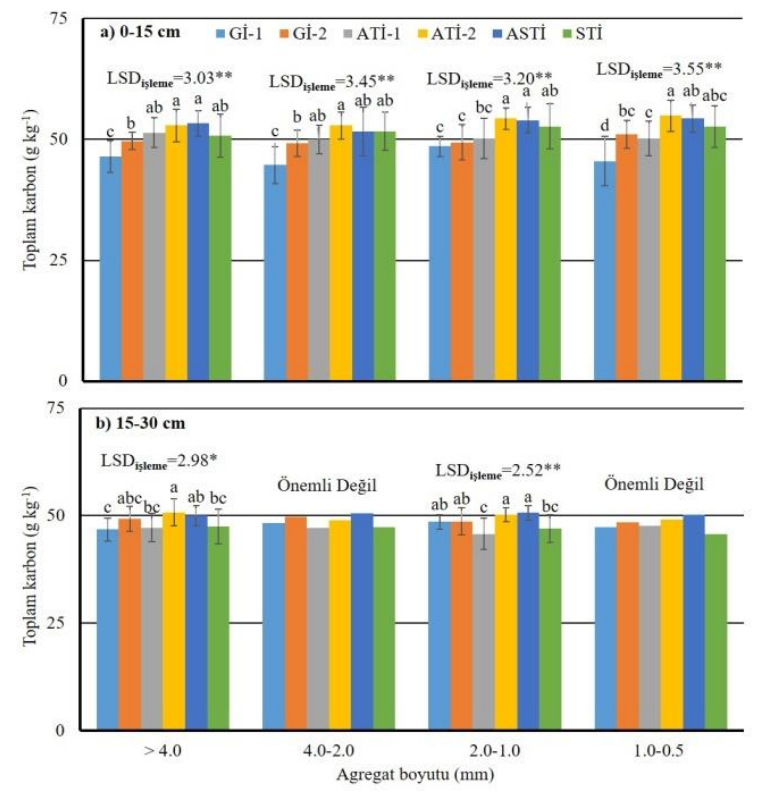

Şekil 1. Farklı toprak işleme uygulamalarının agregatlara bağlı toplam karbona etkileri

Yüzey toprağının agregatlarında geleneksel işleme yöntemlerine (Gİ-1 ve Gİ-2) kıyasla korumalı işleme uygulamalarında (ATİ-1, ATİ-2, ASTİ ve STİ) daha yüksek toplam karbon belirlenmiştir. $\mathrm{Bu}$ durumun nedeni olarak geleneksel işleme yöntemlerinde toprakların alt üst edilerek derin işlenmesi sonucu organik maddenin içerisinde ve aralarında korunduğu agregatların tahrip olması (Havlin ve ark., 1990), bu agregatların bozulması ve toprakta artan sicaklık ve havalanma ile organik maddenin ayrışmaya uğraması olduğu söylenebilir. Yapılan birçok çalışmada da bu araştırmada elde edilen bulguları destekler nitelikte olup, korumalı işleme yöntemlerinde geleneksel işleme yöntemlerine kıyasla daha fazla toplam karbon bulunduğu rapor edilmiştir (Pinherio ve ark. 2004; Bhattacharyya ve ark. 2009; Jacobs ve ark., 2009; Huang ve ark., 2015; Kabiri ve ark., 2015).

$0-15 \mathrm{~cm}$ derinlikte bütün uygulamalar ve bütün agregat boyutları dikkate alındığında korumalı işleme uygulamalarından biri olan ATİ-2 yöntemi agregatlarda en yüksek toplam karbon birikimini sağlamıștır (Şekil 1a). Bunun nedeni söz konusu bu işleme yönteminde kullanılan rototiller aletinin toprak üzerindeki etkisi olabilir. Zira ATİ-2 yönteminde hem birinci ürün hem de ikinci ürün yetiştiriciliğinde toprak işlemesi amaciyla rototiller aleti kullanılmaktadır. $\mathrm{Bu}$ aletin toprağı yüzeysel olarak $(13-15 \mathrm{~cm})$ işlemesi, toprağ ve devirmeden olduğu yerde parçalaması ve bu esnada bitkisel artıkları da daha fazla parçalayarak toprağa karıştırmasından ötürü topraktaki toplam karbonu arttırdığına neden olduğu düşünülmektedir. $\mathrm{Bu}$ aletin toprağı derin işlememesi, toprağı devirmemesi ve alt-üst etmemesi nedeniyle topraktaki havalanmanın ve sıcaklığın düşük olmasına yol açtığı ve bu nedenle toprakta daha fazla karbon bağlamasına neden olduğu sanılmaktadır. Yapılan bir çok çalışmada pulluk ve ağır diskli tırmık gibi aletler ile toprağın derin ve kesilerek devrilmesi sonucunda toprakta artan havalanma ve sıcaklığa bağ lı olarak mineralizasyonun hızlandığı ve bu nedenle topraktaki organik karbonun azaldığ belirtilmektedir (Nardi ve ark., 1996; Paustian ve ark.,1997; Resck ve ark.,1999; Islam ve Weil, 2000).

Yüzey toprağına kıyasla $15-30 \mathrm{~cm}$ derinlikte korumalı işleme altındaki agregatlarda tutulan toplam karbon değerleri azalış gösterirken geleneksel işleme altındaki agregatlarda tutulan toplam karbon değerleri nispeten artış göstermiştir (Şekil 1b). Diğer bir ifade ile derinlik artışı ile birlikte korumalı işleme uygulamaları altındaki agregatlarda daha düşük toplam karbon değerleri elde edilmiştir. Yapılan değişik bir çok araştırmada da derinlikteki artışla birlikte korumalı işleme yöntemleri altında farklı agregat büyüklüklerindeki toplam karbonun azaldığı rapor edilmiştir (Gal ve ark., 2007; Abid ve Lal, 2008; Andruschkewitsch ve ark., 2013; Hou ve ark., 2013). Bu sonuç nispeten doğal ve beklenen bir durumdur. Zira geleneksel işleme uygulamalarında toprakların derin, parçalayıcı ve her bir yıl içerisinde 5-6 kez işlenmesi ile birlikte organik madde kaynağı olan toprak yüzeyindeki anızlar geleneksel işleme yöntemlerinde daha derinlere karıştırılmakta buna karşı korumalı işleme uygulamalarında hasat artıkları toprak yüzeyinde veya yüzey derinliğinde $(0-15 \mathrm{~cm})$ kalmakta ve bu nedenle korumalı işleme yöntemlerine kıyasla geleneksel işleme yöntemlerinde $15-30 \mathrm{~cm}$ derinlikte daha fazla toplam karbon artışı meydana gelmektedir (Heenan ve ark., 
2004; Gal ve ark., 2007).

Yapılan bir çok çalışmada, azaltılmış ve sıfır işleme (no-till) yöntemlerinin topraklarda karbon bağlanmasını arttırdığı kanıtlanmış bir gerçek olduğu (Campbell ve ark., 1995; Follet ve ark., 2005), ayrica toprakta ve artık (residual) karbonu koruyan ve potansiyel olarak da bağlanan karbon miktarını arttıran işleme sitemleri başında korumalı işleme yöntemleri geldiği rapor edilmiştir (Lal ve ark., 1998; Lal ve ark., 1999).

\subsection{Toprak işleme yöntemlerinin agregatlara bağll toplam azota etkisi}

İşleme uygulamalarının farklı büyüklükteki agregatlarda tutulan toplam azot içerikleri üzerinde $\% 1$ düzeyinde önemli etkileri olduğu belirlenmiştir (Şekil2). İşleme yöntemlerinin $0-15 \mathrm{~cm}$ derinlikte toplam azot içeriğine etkileri genel olarak bütün agregat boyutları (>4.0 mm, 4.0-2.0 mm, 2.0-1.0 mm ve 1.0-0.5 mm) için istatistiksel olarak ATİ-1 $>$ Gİ-2 $\geq$ Gİ-1 $>$ ATİ-2 $>$ STI $\geq$ ASTİ şeklinde sıralanmıştır (Şekil 2a). Bütün agregat boyutlarında en yüksek toplam azot içeriği korumalı işleme yöntemlerinden biri olan ATİ-1 yönteminde elde edilirken en düşük toplam azot içeriği yine korumalı işleme yöntemlerinden olan STİ ve ASTİ yöntemlerinde elde edilmiştir (Şekil 2a).

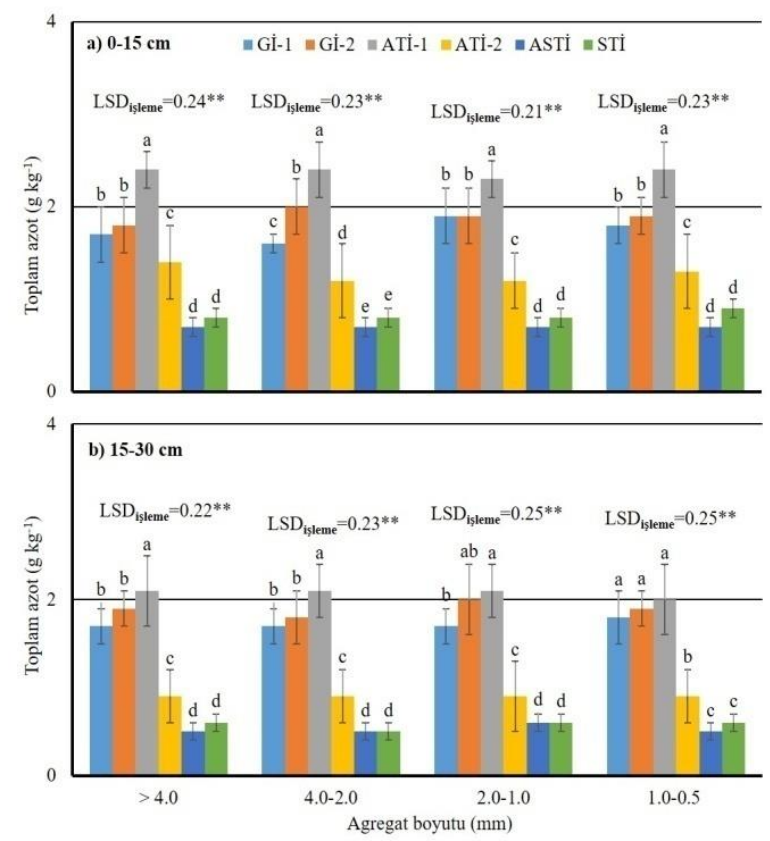

Şekil 2. Farklı toprak işleme uygulamalarının agregatlara bağlı toplam azota etkileri

İşleme yöntemlerinin $\quad 0-15 \quad \mathrm{~cm}$ derinlikteki agregatlarda tutulan toplam azot değerleri incelendiğinde, azaltılmış işleme uygulamalarından biri olan ATİ-1 yöntemi en iyi toplam azot birikimi sağladığ1 görülmektedir. Korumalı işleme uygulamalarının (ATI-1, ATİ-2, ASTI ve STİ) toprak işlemedeki işleme derinliği, sayısı ve yoğunlukları kendi aralarında kıyaslandığında, ATİ-1 yöntemi korumalı işleme uygulamaları arasında toprağın en fazla ve en derin işlendiği yöntemdir. Korumalı işleme yöntemleri arasında toprağın hiç işlenmediği (STİ) ve bir yıl içerisinde sadece kışlık ekim için (buğday) toprağın bir kez işlendiği (ASTI) yöntemleri arasında istatistiki olarak fark belirlenmemiş olup bu iki işleme yöntemi altında bütün agregat boyutlarında en düşük toplam azot değerleri saptanmıştır. Buradan anlaşılacağı gibi korumalı işleme uygulamalarında toprak işleme derinliği ve yoğunluğu azaldıkça buna paralel olarak toprakta depolanan toplam azot içeriği de azalmıştır.

Geleneksel işleme yöntemleri ATİ-1 yöntemi dışındaki korumalı işleme yöntemlerine kıyasla bütün agregat boyutlarında daha yüksek toplam azot birikimi sağlamışlardır. Bazı araştırmacılara göre, diğer toprak işleme sistemleri ile karşılaştırıldığında sıfır işleme sistemi, daha fazla toplam azot birikimi sağlarken (Sisti ve ark., 2004; Steinbach ve Alvarez, 2006; Jacobs ve ark., 2009; Du ve ark., 2010), diğerleri farklı sonuçlar elde etmişlerdir (Alvarez ve ark., 1998; Costantini ve ark., 2006). Birbirinden farklı olan bu sonuçlar deneme koşullarındaki toprak ve iklim koşulları, geçmiş arazi yönetim uygulamaları, ürün rotasyon çeşitliliği, örnekleme derinlikleri ve zamanı ve araştırmalarda çalışılan agregat boyut dağılımındaki farklılıklardan kaynaklanıyor olabilir (Alvarez ve ark., 2014).

İşleme uygulamaların $15-30 \mathrm{~cm}$ derinlikte farklı agregat büyüklüklerindeki toplam azot içeriğine olan etkileri yüzey toprağında $(0-15 \mathrm{~cm})$ elde edilen sonuçlarla önemli benzerlik göstermektedir. Buna göre bütün agregat boyutlarında olmak üzere en yüksek toplam azot değerleri azaltılmış işleme uygulamalarından biri olan ATİ-1 yönteminde elde edilmiştir (Şekil 2b). Ayrıca 15-30 cm derinlikte farklı büyüklükteki agregatlarda elde edilen toplam azot içerikleri geleneksel işleme yöntemleri altında elde edilen toplam azot değerlerinin $0-15 \mathrm{~cm}$ derinlikteki değerlere benzerlik gösterirken korumalı işleme yöntemleri altında elde edilen değerlerin derinlikteki artışla birlikte azaldığı anlaşılmaktadır (Şekil 2). Yapılan çalışmalarda da genel olarak derinlikteki artış ile birlikte toplam azot değerlerinin azaldığ 1 rapor edilmiştir (Heenan ve ark., 2004; Abid ve Lal, 2008; Hou ve ark., 2013).

Yüzey derinlik olan $0-15 \mathrm{~cm}$ derinlikteki toplam azot değerlerinde olduğu gibi $15-30 \mathrm{~cm}$ derinlikte de ATİ-1 hariç tutulursa geleneksel işleme yöntemlerine göre korumalı işleme uygulamaları altında daha düşük toplam azot değerleri elde edilmiştir (Şekil 2b). Hem 0$15 \mathrm{~cm}$ hem de $15-30 \mathrm{~cm}$ derinlikteki toplam azot değerleri bakımından geleneksel işleme uygulamaları olan Gİ-1 ile anızların yakıldığı Gİ-2 yöntemleri arasında bir fark bulunmamıştır. Ancak korumalı işleme uygulamalar1 olan ATİ-1, ATİ-2, ASTİ ve STİ yöntemleri birbiriyle kıyaslandığında bütün agregat boyutlarında geçerli olmak üzere $15-30 \mathrm{~cm}$ derinlikteki toplam azot birikimine etkileri ATI-1>ATI2>ASTI $>$ STİ şeklinde bir sıralama elde edilmiştir (Şekil 2b). Bu sıralamadan da anlaşılacağı gibi korumalı 
işleme uygulamalarında bile toprak işlemenin yoğunluğu ve sayısı azaldıkça $15-30 \mathrm{~cm}$ derinlikteki toplam azot değerleri de azalmıştır (Şekil 2b). Zira toprakların hiç işlenmediği STİ yöntemi altında (sıfır işleme) en düşük toplam azot değerleri elde edilmiş olup bu yöntemden sonra ikinci sırada en düşük değerler, yıl içerisinde iki ürün yetiştiriciliğinde toprakların sadece kışlık ürün buğday ekim işleminde ağır diskli tırmığın bir kez kullanıldığı ASTİ yönteminde elde edilmiştir.

Diğer bir ifade ile bitkisel artıkların tamamen yüzeyde bırakılarak toprağa karıştırılmadığı (STI) veya toprağın az işlendiği (ASTi) yöntemlerde bütün agregat boyutlarında olmak üzere toprakta daha düşük toplam azot değerleri elde edilmiştir. $\mathrm{Bu}$ durumun nedeni yüzeyde kalan veya toprağa yeterince karıştırılmayan organik artıkların toplam azot değerlerinde azalmaya yol açan ana faktör olabileceği düşünülmektedir. Zira geleneksel işleme uygulamalarında bitkisel ürün artıkları veya bu artıkların yakılmasından arda kalan küllerin derin, parçalayıcı ve toprağı devirici aletlerle toprağın alt katmanlarına karıştııılması sonucunda bu uygulamalar altında daha yüksek toplam azot değerleri elde edilmiştir. Yüzeyde kalan bitki artıklarının pulluk gibi derin aletlerle toprağa karıştırılması durumunda yüzey altı katmanlardaki toplam karbon ve azotun artışına neden olduğu araştırmalarda vurgulanmıştır (Heenan ve ark., 2004; Gal ve ark., 2007).

İşleme yöntemlerinin topraktaki toplam azot içeriğine etkileri ile ilgili olarak yapılan çalışmaların bir çoğunda toplam karbon değerlerinin yüksek olduğu korumalı veya azaltılmış işleme konularındaki toplam karbon içeriğine paralel olarak yüksek toplam azot değerleri de elde edilmiştir (Sisti ve ark., 2004; Steinbach ve Alvarez, 2006; Kahlon ve ark., 2013; Xue ve ark., 2015). Agregat boyutlarındaki toplam azot ile doğrudan ilgili olmamakla birlikte geleneksel işleme uygulamalarına göre azaltılmış veya minimum işlemenin yapıldığı toprakların $15-30 \mathrm{~cm}$ derinliğinde daha yüksek toplam azot değerleri elde edildiği rapor etmişlerdir (Rasmussen ve ark., 1998; Torbert ve ark., 1998; Hao ve ark., 2001). Ancak araştırmamızda her iki derinlikteki (0-15 ve $15-30 \mathrm{~cm})$ yüksek toplam karbon değerlerinin elde edildiği azaltılmış ve sıfır ișleme yöntemleri altında özellikle de ATİ-2, ASTİ ve STİ uygulamalarında daha düşük toplam azot değerleri saptanmıştır. Bunun temel nedeni, topraktaki organik maddenin ayrışmasının henüz tamamlanmadığı ve/veya ayrışma hızının yavaş seyrettiğidir (Özbek ve ark., 1994; Six ve ark., 2000; Blume ve ark., 2010). Zira literatüre göre $\mathrm{C} / \mathrm{N}$ oranı $20^{\prime}$ den büyük ise topraktaki organik maddenin tamamen ayrışmadığ 1 kabul edilmektedir (Özbek ve ark., 1994). İşleme konularına ait toplam karbon, azot ve araştırma alanı topraklarına ait yüksek $\mathrm{CaCO}_{3}$ değerlerinden (Çelik ve ark., 2009) yararlanılarak yaklaşık değerlerle hesaplanan $\mathrm{C} / \mathrm{N}$ değerlerine göre her iki derinlikte ve tüm agregat boyutlarında ATİ-2, ASTİ ve STİ konularında elde edilen $\mathrm{C} / \mathrm{N}$ oranları 21 ile 40 arasında değişmektedir. $\mathrm{Bu}$ konulara ait yüksek $\mathrm{C} / \mathrm{N}$ oranları toplam karbon değerlerinin yüksek olduğu korumalı işleme uygulamalarında toplam azot değerlerinin düşük çıkmasının nedenini daha iyi anlaşılır kılmaktadır.

\section{Sonuç}

Elde edilen bu sonuçlar, Çukurova bölgesi gibi iklim bakımından avantajlı özelliklere sahip olan alanlarda bir yıl içerisinde iki ürün almak amaciyla, toprakların geleneksel işleme yöntemleri ile çok çeşitli ve parçalayıcı aletlerle 5-7 kez derin işlenmesi durumunda makro agregatlarda önemli bozulmalara yol açtığını ve bu agregatlarda tutulan toplam karbonu azalttığını göstermiştir. Buna karşın farklı büyüklükteki agregatlarda tutulan toplam azot değerleri ise ATİ-1 yöntemi dışındaki korumalı işleme yöntemlerine kıyasla geleneksel işleme yöntemleri altında daha yüksek bulunmuştur.

Atmosferik $\mathrm{CO}_{2}$ ile karbon depolanması ve değişimi için en önemli karasal havuzlardan biri toprağın organik karbonu olduğu son y1llardaki çalışmalarla da kabul görmüş bir gerçektir. Bu nedenle topraktaki karbonu koruyan ve potansiyel olarak bağlanan karbon miktarını arttıran işleme sitemlerinin başında ise korumalı işleme yöntemleri gelmektedir. Tarımsal üretimde geleneksel işleme sistemleri yerine korumalı işleme sistemlerinin kullanılması durumunda, agregatlar içerisinde özellikle toplam karbon tutulmasında önemli gelişmeler sağladığı belirlenmiştir. Ayrıca azaltılmış işleme yöntemlerinden biri olan ATİ-1 yönteminde her iki derinlikte $(0-15$ ve $15-30 \mathrm{~cm}$ ) ve bütün agregat boyutlarındaki toplam azotun depolanmasında en yüksek değerler elde edilmiştir. Geleneksel işleme uygulamalarından biri olan Gİ-2 yönteminde hasat/anız artıklarının yakılması topraktaki agregatlara bağlı toplam karbon üzerinde olumsuz bir etkisi belirlenmemiş olup, bunun aksine anızların yakılmadığı işleme konusu olan Gİ-1'e göre her iki derinlikte özellikle $>4.0 \mathrm{~mm}$ ve $4.0-2.0 \mathrm{~mm}$ agregatlarda daha yüksek toplam karbon içerdiği saptanmıştır. Ancak total azot bakımında bu iki işleme yöntemi arasında fark bulunmamıştır.

Azaltılmış işleme uygulamalarının agregatlara bağlı toplam karbon ve azot üzerine olumlu etkileri olmuştur. $\mathrm{Bu}$ nedenle organik madde içeriği düşük, strüktür gelişimi zayıf, erozyona karşı direnci az, $\mathrm{CO}_{2}$ salınımının çok olduğu ve toprakların kalite göstergelerini oluşturan fiziksel, kimyasal ve biyolojik özellikleri zayıf olan topraklarda geleneksel işleme yerine korumalı işleme sistemleri kullanılmalı veya sıfır işlemeye adapte edilmiş azaltılmış işleme sistemlerinin kullanımı önerilmektedir.

\section{Teşekkür}

$\mathrm{Bu}$ araştırma, Çukurova Üniversitesi Bilimsel Araştırma Projeleri Koordinasyon Birimi tarafindan FBA-2015-4935 no'lu proje kapsamında desteklenmiştir. $\mathrm{Bu}$ projeyi destekleyen Çukurova Üniversitesi Bilimsel Araştırma Koordinasyon Birimine 
ve ayrıca makalenin değerlendirilmesi aşamasında değerli görüş ve önerilerini belirten hakemlere teşekkür ederiz.

\section{Kaynaklar}

Abid, M., Lal, R., 2008. Tillageanddrainageimpact on soilquality I. Aggregatestability, carbonandnitrogenpools. SoilandTillageResearch, 100: 89-98.

Alvarez, C.,Alvarez, C.R., Costantini, A., Basanta, M., 2014. Carbon and nitrogen sequestration in soilsunderdifferentmanagement in the semi-arid Pampa (Argentina). Soil and Tillage Research, 142: 25-31.

Alvarez, R.,Russo, M.E., Prystupa, P., Scheiner, J.D., Blotta, L., 1998. Soil carbon pool sun der conventional and notillage systems in the Argentine Rolling Pampa. Agronomy Journal, 90: 138-143.

Andruschkewitsch, R.,Geisseler, D., Koch, H., Ludwig, B., 2013. Effects of tillage on contents of organic carbon, nitrogen, water stable aggregate sandlight fraction for four different long-termtrials. Geoderma, 192: 368-377.

Barbera, V.,Poma, I., Gristina, L., Novara, A., Egli, M., 2012. Long-term cropping systems and tillage management effects on soil organic carbon stock and steady state level of $\mathrm{C}$ sequestrationrates in a semiarid environment. Land Degradationand Development, 23: 82-91.

Bhattacharyya, B.,Prakash, V., Kundu, S., Srivastva, A.K., Gupta, H.S., 2009. Soilaggregationandorganicmatter in a sandyclayloamsoil of the Indian Himalaya suder different tillage and crop regimes. Agriculture, Ecosystemsand Environment, 132: 126-134.

Blanco-Canqui, H., Lal, R., 2006. Tensile Strength of Aggregates. Encyclopedia of Soil Science, vol. 45-48. The Ohio State University, Columbus, OH, USA.

Blume, H.P.,Brümmer, G.W., Horn, R., Kandeler, E., KögelKnabner, I., Kretzschmar, R., Stahr, K., Wilke, B.M., 2010. Scheffer/Schachtschabel. Lehrbuch der Bodenkunde.

Campbell, C.A.,Mc Conkey, B.G., Zentner, R.P., Dyck, F.B., Selles, F., Curtin, D., 1995. Carbonsequestration in a Brown Chernozem as affected by tillage and rotation. Canadian Journal of Soil Science 75: 449-458.

Cannell, R.Q.,Hawes, J.D., 1994. Trends in tillagepractices in relationtosustainablecropproductionwithspecialreferenceto temperateclimates. Soi land Tillage Research, 30: 245282.

Christensen, B.T., 2001. Physical fractionation of soil and structural and functional complexity in organic matter turnover. European Journal of Soil Science, 52: 345-353.

Costantini, A., De-Polli, H., Galarza, C., Rossiello, R.P., Romaniuk, R. 2006. Total and mineralizable soil carbon as affect byt illage in the Argentinean Pampas. Soil and Tillage Research, 88: 274-278.

Çelik, İ.,Ortaş, İ., Bereket Barut, Z., Gök, M., Sarıyev, A., Demirbaş, A., Akpınar, Ç., Tülün, Y., 2009. Farklı Toprak İşleme Sistemlerinin Toprak Kalitesi Parametrelerine ve Ürün Verimine Etkileri. TÜBİTAK-TOVAK, Araştırma projesi Sonuç Raporu.

Dexter, A.R., 1988. Advances in characterization of soil structure. Soil and Tillage Research, 11: 199-238.

Du, Z., Ren, T., Hu, C., 2010. Tillage and residueremoval effects on soil carbon and nitrogen storage in the North China Plain. Soil Science Society of America Journal, 74(1): 196-202.

Follet, R.F.,Castellanos, J.Z., Buenger, E.D., 2005. Carbon
Dynamics and sequestration in an irrigated Vertisol in Central Mexico. Soil and Tillage Research 83: 148-158.

Gal, A.,Vyn, T.J., Micheli, E., Kladivko, E.J., McFee, W.W., 2007. Soil carbon and nitrogen accumulation withlong-termno-till versus moldboard plowing over estimated with tilled-zone sampling depths. Soil and Tillage Research, 96: 42-51.

Gülez, M., Şenol, S., 2002. Çukurova Üniversitesi Ziraat Fakültesi Toprak Bölümü Deneme Alanının Detaylı Toprak Etüd ve Haritalaması. Çukurova Üniversitesi Ziraat Fakültesi Dergisi, 17: 103-110.

Hao, X.,Chang, C., Lindwall, C.W., 2001. Tillage and crop sequence effects on organi ccarbon and total nitrogen content in an irrigated Alberta soil. Soil and Tillage Research, 62: 167-169.

Havlin, J.L.,Kissel, D.E., Maddux, L.D., Claassen, M.M., Long, J.H., 1990. Crop rotation and tillage effects on soil organic carbon and nitrogen. Soil Science Society of America Journal, 54: 448-452.

Heenan, D.P.,Chan, K.Y., Knight, P.G., 2004. Long-term impact of rotation, tillage and stubble management on the loss of soil organic carbon and nitrogen from a Chromic Luvisol. Soil and Tillage Research, 76: 59-68.

Hou, X.,Li, R., Jia, Z., Han, Q., 2013. Effect of Rotational Tillage on Soil Aggregates, Organic Carbon and Nitrogen in the Loess Plateau Area of China. Pedosphere, 23: 542548.

Huang, M.,Liang, T., Wang, L., Zhou, C., 2015. Effects of notillage systems on soil physical properties and carbon sequestration under long-term wheat-maize double cropping system. Catena, 128: 195-202.

Islam, K.R.,Weil, R.R. ,2000. Land useeffects on soilquality in a tropical forest ecosystem of Bangladesh. Agriculture, Ecosystems and Environment, 79(1): 9-16.

Jacobs, A.,Rauber, R., Ludwig, B., 2009. Impact of reduced tillage on carbon and nitrogen storage of two Haplic Luvisol safter 40 years. Soil and Tillage Research, 102: $158-164$

Jiang, X., Wright, A.L., Wang, J., Li, Z., 2011. Long-term tillage effects on the distribution patterns of microbialbiomass and activities within soil aggregates. Catena, 87: 276-280.

Kabiri, V.,Raiesi, F., Ghazavi, M.A., 2015. Sixyears of different tillage system saffecte daggregate-associated SOM in a semi-arid loam soil from Central Iran. Soil and Tillage Research, 154: 114-125.

Kahlon, M.S., Lal, R., Ann-Varughese, M., 2013. Twenty two years of tillage and mulching impacts on soil physical characteristics and carbon sequestration in Central Ohio. Soi land Tillage Research, 126: 151-158.

Kasper, M.,Buchan, G.D., Mentler, A., Blum, W.E.H., 2009. Influence of soil tillage systems on aggregat estabilityand the distribution of $\mathrm{C}$ and $\mathrm{N}$ in different aggregat efractions.Soil and Tillage Research, 105: 192-199.

Kushwaha, C.P.,Tripathi, S.K., Singh, K.P., 2001. Soil organic matter and waters table aggregate sunder different tillage and residue conditions in a tropical dry land agroecosystem. Applied Soil Ecology, 16: 229-241.

Kutilex, M., 2004. Soil hydraulic properties as related to soil structure. Soil and Tillage Research, 79, 175-184.

Lal, R., 1998. Methods for assessment of soil degradation. In: Advances in Soil Science. CRP press, Boca Raton, FL.

Lal, R.,Kimble, J.M., Follett, R.F., Cole, C.V., 1998. The Potential of U.S Cropland to Sequester Carbon and Mitigatethe Greenhouse Ef ect. Ann Arbor Press, Chelsea, MI, 128 pp. 
Lal, R.,Kimble, J.M., Follett, R.F., Cole, C.V., 1999. Management of U.S. crop land to sequester carbon in soil. Journal of Soiland Water Conservation 54: 374-381.

Nardi, S.,Cocheri, G., DellAgnola, G., 1996. Biological activity of humus. In: Piccolo, A. (Ed.), Humic Substances in Terrestrial Ecosystems. Elsevier, Amsterdam, pp. 361406.

Özbek, H., Kaya, Z., Gök, M., Kaptan, H., 1993. Toprak Bilimi. P. Schachtschabel, H.-P. Blume, G. Brummer, K.H. Hartge, U. Schwertmann (Çeviri). Ç.Ü. Zir. Fak. Ders Kitapları Yay. No: 16.

Pagliai, M.,Vignozzi, N., Pellegrini, S., 2004. Soil structure and the effect of management practices. Soil and Tillage Research, 79: 131-143.

Paustian, K.,Collins, H.P., Paul, E.A., 1997. Management controls on soil carbon. In: Paul, E.A., et al. (Eds.), Soil Organic Matter in Temperate Agroecosystems, Long term Experiments in North America. CRC Press, Boca Raton, FL, USA, pp. 15-49.

Pinheiro, E.F.M.,Pereira, M.G., Anjos, L.H.C., 2004. Aggregate distribution and soil organicmatter under differentt illage systems for vegetable crops in a Red Latosol from Brazil. Soil and TillageResearch, 77: 79-84.

Rasmussen, P.E.,Albrecht, S.L., Smiley, R.W., 1998. Soil C and $\mathrm{N}$ change sunder tillage and cropping systems in semiarid Pacific Northwest agriculture. Soi land Tillage Research, 47: 197-205.

Resck, D.V.S.,Vasconcellos, C.A., Vilela, L., Macedo, M.C.M., 1999. Impact of conversion of Brazilian Cerradosto crop land and pastureland on soil carbon pooland dynamics. In: Lal, R.,Kimble, J.M., Stewart, B.A. (Eds.), Global Climate Change and Tropical Ecosystems. Adv. Soil Sci. CRC Press, Boca Raton, FL, pp. 169-196.

Sisti, C.P.J.,Dos Santos, H.P., Kohhann, R., Alves, B.J.R., Urquiaga, S., Boddey, R.M., 2004. Changes in carbon and nitrogen stocks in soil under 13 years of conventional orzero tillage in southern Brazil. Soil and TillageResearch, 76: $39-58$.

Six, J.,Elliott, E.T., Paustian, K., 2000. Soil Macro aggregateTurnover and Microaggregate Formation: A Mechanism for $\mathrm{C}$ Sequestration under No-Tillage Agriculture. Soil Biology and Biochemistry, 32(14): 20992103.

Soil Survey Staff, 1999. Soil taxonomy: a basic system of soil classification for making and interpreting soil surveys, 2nd edition. Agriculture Handbook, vol. 435.USDA, NRCS., US Government Printing Office, Washington DC.

Steinbach, H.S.,Alvarez, R., 2006. Changes in soil organic carbon contents and nitrousoxide emissions after introduction of no-till in Pampean agroecosystems. Journal of Environmental Quality, 35: 3-13.

Torbert, H.A., Potter, K.N., MorrisonJr, J.E., 1998. Tillage intensity and crop residue effects on nitrogen and carbon cycling in a Vertisol. Communications in Soil Science and Plant Analysis, 29(5-6): 717-727.

Xue, J., Pu, C., Liu, S., Chen, Z., Chen, F., Xiao, X., Lal, R., Zhang, H., 2015. Effects of tilla gesystems on soil organic carbon and total nitrogen in a double paddy cropping system in Southern China. Soil and TillageResearch, 153: $161-168$ 